\title{
Traumatic brain injury: future assessment tools and treatment prospects
}

\author{
Steven R Flanagan' \\ Joshua B Cantor ${ }^{2}$ \\ Teresa A Ashman² \\ 'New York University School \\ of Medicine, The Rusk Institute \\ of Rehabilitation, New York, NY, \\ USA; ${ }^{2}$ Department of Rehabilitation \\ Medicine, Mount Sinai School \\ of Medicine, New York, NY, USA
}

\begin{abstract}
Traumatic brain injury (TBI) is widespread and leads to death and disability in millions of individuals around the world each year. Overall incidence and prevalence of TBI are likely to increase in absolute terms in the future. Tackling the problem of treating TBI successfully will require improvements in the understanding of normal cerebral anatomy, physiology, and function throughout the lifespan, as well as the pathological and recuperative responses that result from trauma. New treatment approaches and combinations will need to be targeted to the heterogeneous needs of TBI populations. This article explores and evaluates the research evidence in areas that will likely lead to a reduction in TBI-related morbidity and improved outcomes. These include emerging assessment instruments and techniques in areas of structural/chemical and functional neuroimaging and neuropsychology, advances in the realms of cell-based therapies and genetics, promising cognitive rehabilitation techniques including cognitive remediation and the use of electronic technologies including assistive devices and virtual reality, and the emerging field of complementary and alternative medicine.
\end{abstract}

Keywords: traumatic brain injury, assessments, treatments

\section{Traumatic brain injury future prospects}

Traumatic brain injury (TBI) is an extremely common condition, accounting for 50,000 deaths and 235,000 hospitalizations yearly (Langlois et al 2004). The prevalence of individuals with chronic TBI-related problems in the US is 5.3 million (Cohen et al 2007; Thurman et al 1999) with many manifesting a combination of physical, cognitive and behavioral problems. Although this figure is extremely large, it may underestimate the true burden of TBI, as many individuals with milder injuries are often unknown to the medical system (Krause and Arthur 1999). This is partly because physical impairments, which are easily detectable, are frequently mild or absent after TBI, while the more common disabling problems of cognitive and behavioral impairments are often overlooked or misdiagnosed by medical professionals. However, it is the latter group of problems that prevent participation in expected and desired societal roles and result in the greatest burden associated with TBI. In the coming decades, the aging population will make this problem even worse, as older individuals are at increased risk of TBI and generally have poorer outcomes. This will greatly increase the overall prevalence of TBI and add to the societal burden presented by more individuals requiring both medical and custodial care.

Although considerable strides have been made in decreasing overall TBI-related mortality by the application of evidence-based medicine, many individuals develop chronic problems, often resulting in life-long disability. While some pilot projects have reported promising findings, such as decreasing 30-day mortality with progesterone (Wright et al 2007), most studies examining effectiveness of post-acute interventions have failed to definitively demonstrate a therapeutic effect, which is in 
part because of an inadequate understating of both normal and pathological cerebral processes.

Future treatment of TBI will require a far more detailed understanding of normal cerebral anatomy and physiology as well as the pathological and recuperative responses that result from trauma than is currently known. Greater clarity is required regarding normal brain function as it applies to development throughout the lifespan, adaptive responses to disease and trauma, as well as to the physiological interactions between various cerebral regions that permit both simple and complex cognitive processes. Given the staggering prevalence of TBI and its impact on activity and participation, medical science has expanded its search to better assess brain function and the factors that impact injury severity and outcome. Not only will new therapies be based on this enhanced understanding, but also more specific treatments will likely be better directed to individuals possessing unique characteristics. This article will explore emerging assessment instruments, advances in the realms of cell-based therapies, genetics, promising new rehabilitation techniques, and integrative treatments that combine both complementary and alternative approaches with typical Western treatments that will likely lead to a reduction in TBI-related morbidity and improved outcomes.

\section{Neuroimaging}

Traditional imaging techniques, such as computerized tomography (CT) and conventional magnetic resonance imaging (MRI) have proven to be highly effective in identifying macroscopic lesions, which is a necessary component in managing acute trauma. However, they have marked limitations in assessing microscopic lesions and cerebral physiology, such as those associated with diffuse axonal injury (DAI) and metabolic alteration. Furthermore, they offer little insight into the normal physiology associated with behavior and cognition. These issues are being more effectively addressed with newer neuroimaging technologies that are leading science to a more comprehensive understanding of the brain, both through imaging its physiology during various functional tasks and finer in-vivo microscopic analysis of pathological processes and molecular composition in both normal and pathological conditions. Although these techniques will provide considerable insight into injuries of varying severity, it may be particularly useful in identifying individuals with TBI. Typically, individuals with mild TBI have normal appearing neuroimaging studies despite manifesting cognitive and behavioral problems. It is possible that enhanced analysis of brain function and anatomy following mild TBI may assist in delineating the neurophysiologic basis of post-concussion symptoms. Given the limitations of conventional imaging technologies, it is not surprising that they are poorly prognostic of outcomes (Diaz-Marchan et al 1996) and offer little information regarding the assessment of efficacy of TBIrelated treatments. As the mechanisms of cerebral injury and repair are better delineated through enhanced imaging, new assessment and treatment modalities will be developed that can be applied with greater specificity than currently available to individuals with TBI.

\section{Structural/chemical imaging Diffusion tensor imaging}

Diffuse axonal injury (DAI) is felt to be a major contributor to morbidity following TBI, yet because it occurs at a micro- rather that macroscopic level, it is poorly imaged on standard CT and MRI scans. Diffusion tensor imaging (DTI), however, generates images by taking advantage of the variability of both the speed and direction of water diffusion in-vivo. Water diffuses faster along an axon, a phenomenon known as anisotropy, as opposed to across it, a phenomenon known as isotropy. White matter tracts manifest large fractional anisotropy (FA) values, which can be assessed by diffusion tensor technology. This permits an in-vivo investigation of fiber tract integrity that has been correlated with histopathological evidence of DAI (MacDonald et al 2007).

DTI has been shown to provide evidence of axonal injury in the presence of normal standard MR imaging (Nakayama et al 2006), the extent and quantity of white matter injury (Xu et al 2007) and the location of maximum white matter tract abnormality associated with motor impairment postTBI (Yasokawa et al 2007). FA values have been correlated with both injury severity and outcomes (Benson et al 2007; Huisman et al 2004; Wozniak et al 2007). Along with various other imaging modalities, it has the potential to better delineate the normal development of fiber tracts that occur in the brains of children and adolescents as they acquire increasingly complex cognitive capabilities, such as executive skills, that often fail to develop following pediatric TBI. DTI in association with other diffusion weighted images, permits a greater understanding of the pathophysiological process of axonal injury. It does so by examining the individual components and time course responsible for decreased anisotrophy, such as edema and axonal truncation, potentially identifying a therapeutic window for future treatments designed to ameliorate DAI (Newcombe et al 2007). 


\section{Magnetic resonance spectroscopy}

Magnetic resonance spectroscopy (MRS) analyzes the concentrations of various metabolites in specific cerebral regions, which in pathological states differ from healthy tissue. The hardware for MRS is similar to standard MRI, requiring only additional software to provide analysis and imaging. Data are presented from either a single volume of brain, known as single voxel spectroscopy, or as a $2 \mathrm{D}$ or 3D analysis obtained simultaneously over a wider region, known as magnetic resonance spectroscopy imaging (MRSI). $\mathrm{N}$-acetylaspartic acid (NAA) is present only in neuronal tissue and is one of several key cerebral metabolites measured by MRS. Lower than normal levels of NAA are indicative of either neuronal loss or abnormal changes in cellular function (Demougeot et al 2001), which is associated with poorer outcomes post-TBI even in the presence of normal appearing standard neuroimages (Garnett et al 2000). Other metabolites of interest measured by MRS include creatine (energy utilization marker), choline (marker of cell membrane disruption, inflammation and changes in myelination), myo-inositol (astrocyte marker), glutamate and lactate, which along with NAA have been correlated to various outcomes when obtained at various times post-TBI (Marino et al 2007; Shutter et al 2004; Signoretti et al 2002).

MRS appears to be an effective means to assess for injury after mild TBI, revealing whole brain reductions in NAA associated with cerebral atrophy despite the absence of focal lesions detected on conventional MRI. This provides strong evidence that mild TBI can result in widespread damage (Cohen et al 2007). Additional MRS data suggest that older individuals are susceptible to a greater degree of damage occurring from comparable injury severities than their younger counterparts, which may partially account for poorer outcomes in the elderly (Cohen et al 2007). MRS data can provide information on TBI-induced physiological changes, cerebral regions susceptible to injury, individual susceptibility to injury, and the predictive role of metabolic alterations on outcomes post-TBI not feasible with conventional imaging. Longitudinal MRS studies can examine the extent and location of concentration changes over time in association with specific cognitive abilities. This provides information regarding the physiological and chemical modifications that impact either favorably or unfavorably on recovery occurring over time post injury (Yeo et al 2006), although further studies are warranted to determine the best times to acquire data. With greater understanding provided by MRS regarding the molecular changes associated with the acute and reparative processes of TBI and at what time post-injury these changes occur, comes the possibility of developing treatments to ameliorate pathological alterations and improve outcomes.

\section{Functional neuroimaging}

\section{Functional magnetic resonance}

Functional MRI (fMRI) assesses the combination of regional blood flow and local metabolic activity that occurs during cerebral activity. It takes advantage of the differing magnetic properties of oxygenated and de-oxygenated hemoglobin, known as the blood oxygen level difference (BOLD) response. The BOLD response is altered during functional activity and is represented as a bright signal on fMRI, identifying a region that is relatively more metabolically active than surrounding tissue. It offers good temporal and spatial resolution, both of which are better than those obtained by either SPECT or traditional PET scans, and the lack of radiation permits multiple imaging. However, several factors impact the interpretation of fMRI data, including a subject's ability to fully cooperate, medication effects, adequacy of cerebral blood flow, cerebral dominance, and inadvertent subject movement during image acquisition. When interpreting data, it is important to consider the multitude of possible reasons accounting for altered activation patterns, such as establishment of alternative pathways, practice effects, or differences in performance difficulty that exist between injured subjects and normal controls. One must also consider lesion location and size, time from injury, age, and study design (crosssectional versus longitudinal). Also, only simple functional tasks can be performed in the scanner, limiting its utility. It is currently used as a research tool, although in the future it may be used to guide treatment by better delineating regions responsible for cognitive processes, examining changes in activation over time and in response to specific treatments, and assist in determining both optimal dosing and timing of treatments.

\section{Functional near infrared spectroscopy}

Functional near infrared spectroscopy (fNIRS) is an emerging technology that assesses optical properties of tissues in-vivo, permitting investigation of cerebral metabolism. Because oxygenated and deoxygenated hemoglobin have unique optical characteristics, fNIRS can measure functional activity in-vivo, just as fMRI does by measuring the magnetic properties of the same compounds. Researchers have demonstrated fNIRS ability to assess cerebral activity in humans associated with motor or cognitive tasks (Villringer Chance 1997).

Although research examining its utility to assess function after TBI is limited to date, it offers some potential advantages 
over fMRI in that it is a portable system that it is less susceptible to motion artifacts, is less expensive and permits examination of changes during tasks in a more ecologically valid environment. Additionally, obtaining fNIRS is not prevented by the host of contraindications associated with MRI. Accordingly, it offers the possibility of imaging cerebral activity associated with activities not feasible within a MR scanner and in environments more appropriate for the behavior or function. Its portability may also make it a means to assess metabolic changes during specific rehabilitation activities, offering good temporal resolution that may provide opportunities to better develop treatments and assess their physiological underpinnings.

Although it is an emerging technology, some studies have shown correlations with fMRI (Obrig et al 2000; Okamoto et al 2004), suggesting it is a promising venue to examine cerebral activity in more comfortable and varied settings, realizing that additional studies are needed to better correlate the two technologies. However, current fNIRS technology permits imaging only through the top $2-3 \mathrm{~mm}$ of cerebral cortex and $1 \mathrm{~cm}$ lateral to the topical sensors, with other difficulties persisting regarding the use of cranial reference points, reduction of the optical signal by non-cerebral tissue, the impact of pigmentation on signal detection and limited spatial resolution (Irani et al 2007).

\section{Transcranial magnetic stimulation}

Non-invasive stimulation produced by magnetic pulses or direct current offers the opportunity to study the functional neuroanatomy of the brain and is a means to test hypotheses pertaining to cognitive neurosciences. Transcranial magnetic stimulation (TMS) uses short magnetic pulses that are provided in three different patterns (single pulse, paired pulse or repetitive pulses), resulting in either an increase or decrease in cortical excitability. Altering cortical excitability permits a non-invasive means to examine the impact of "virtual lesions" in otherwise healthy tissue as well as the impact of enhanced excitability on various cognitive or motor tasks. This will lead to a more detailed understanding of cerebral physiology and the neuroanatomical correlates of impaired function resulting from disease or trauma. Current applications of TMS after TBI include measuring the excitability of central motor pathways, mapping cortical representations, and predicting motor recovery (Caramia et al 1996; Netz et al 1997; Turton et al 1996) while possible future uses may include it as a therapy for various brain injury related cognitive and motor impairments.

Repetitive TMS (rTMS) applies a repeated train of magnetic pulses at either low or high frequencies, typically producing a suppression or enhancement of cortical excitability respectively (Berardelli et al 1998; Chen et al 1997; Muellbacher et al 2000). The change in excitability incurred by rTMS has been shown to last beyond the application of the magnetic pulses (Peinemann et al 2004), possibly as a result of inducing long-term potentiation (Siebner Rothwell 2003). This lasting change creates an environment that may be supportive of neural plasticity that can be exploited as a means to enhance treatment following TBI. Although studies to date to improve motor and cognitive skills have been small and its efficacy remains uncertain (McElligott et al 2007), several studies suggest it may be a valuable adjunct to traditional rehabilitation techniques to improve function (Butefisch et al 2004; Hummel et al 2005; Khedr et al 2005). Its therapeutic potential has been most studied as a means to treat major depression, predominantly in subjects refractory to pharmacological intervention, by targeting the dorsolateral prefrontal cortex (Fregni et al 2006; McNamara et al 2001), with results generally indicating its effectiveness is equivalent to electro-convulsive therapy (Grunhaus et al 2003). Its primary risk is inducing seizures, although strict adherence to recommendations detailing limits on stimulation parameters, monitoring guidelines and contraindications decreases its incidence (Wassermann 2002).

Potential uses of TMS after TBI in the future include enhancing our understanding of neuronal circuits by better delineating their mechanisms, location, timing, lateralization and adaptability to injury and experience (Floel and Cohen 2007) and exploiting its impact on cerebral plasticity to ameliorate brain injury-related morbidity. As opposed to fMRI and PET, it is independent of subject performance, although subcortical structures cannot be directly stimulated by this method.

\section{Magnetoencephalography}

Magnetoencephalography (MEG) involves the detection of magnetic fields generated by electrical currents in the brain in response to neuronal activity, which unlike electrical activity measured by EEG, are not distorted by other tissues. This permits precise spatial localization of its generating source with temporal resolution measured in fractions of a millisecond. MEG therefore permits the tracking of brain activity in real time with precise localization. Data derived from MEG may be integrated with standard MR images to generate magnetic source images (MSI), which provide a visual representation of the activated cerebral region. The precise temporal and spatial resolution of MEG makes it possible to not only examine which regions are activated during specific cognitive 
tasks but also the relative time course of activations, which is critical in understanding cognitive processes that involve geographically discrete brain regions. Abnormalities in MEG signals have been shown to correlate with cognitive difficulties in subjects with mild TBI (Lewine et al 2007). By gaining a more detailed understanding of where and when neuronal circuitry become active and how they change in response to injury and rehabilitation, scientists will gain better insights into cognitive physiology permitting development of more specific treatments and the response to those treatments.

\section{Stem cells}

Stem cells (SC) are naturally occurring immature cells that are both self-generating and pluripotent, possessing the ability under specific conditions to differentiate into various cell types. They are derived from 2 broad sources; the inner cell mass of 4- to 5-day-old fertilized embryos, known as embryonic SC, or adult SC that are obtained from mature tissues such as bone marrow, umbilical cord blood, or the central nervous system. Because of the considerable ethical and political controversy that exists regarding the use of embryonic $\mathrm{SC}$, adult $\mathrm{SC}$ research has become another venue to advance the field in general. Similar to embryonic SC, adult $\mathrm{SC}$ have been shown to develop into phenotypically diverse cell types under specific conditions. Within the CNS, adult neural SC naturally exist in the hippocampus and the subventricular zone, which maintain the ability to generate neurons, astrocytes and oligodendrocytes throughout life (Reynolds and Weiss 1992) and are presumably responsible for some degree of central nervous system homeostasis and repair (Garbuzova-Davis et al 2006). However, the persistent ability to naturally produce neural tissue throughout life cannot sufficiently repair damage and restore lost function resulting from injury and disease, possibly because not enough cells are produced, inability of newly produced cells to migrate to the region of injury or a microenvironment that is poorly conducive for repair (Kim 2007). Enhancing creation of neural tissue from SC, either by increasing endogenous production or exogenously by transplantation of SC made in vitro, represents a novel and promising means to repair CNS damage, reverse neurological impairments and restore function lost to disease or trauma.

Research to date, predominantly in animals, provides some indication of the potential utility of cell-based therapy. Neural cells arising from implanted adult SC have been identified in or close to the region of injuries induced in animals, often associated with functional improvement (Chen et al 2001; Jeong et al 2003; Lee et al 2007; Li et al 2002). This indicates that SC not only maintain the ability to differentiate into more mature neural cells, but that these progeny migrate to the area of injury and may contribute to improved neurological function. Functional improvements in humans have also been reported, but research here is very limited (Bang et al 2005; Kondziolka et al 2000; Savitz et al 2004). Although intuition suggests the neurological improvements observed in these studies arose from replacement of neurons damaged by disease or trauma, definitive conclusions remain elusive. Other possible explanations for improvement include that SC alter the microenvironment by production of growth factors (Sanberg et al 2004), provide some degree of neuroprotection or modulate inflammation (Garbuzova-Davis et al 2006). More research is needed in order to answer this and other questions, which will ultimately help to direct clinical use of $\mathrm{SC}$ in the future.

Several barriers currently exist preventing more vigorous clinical applications of cell based therapies, including the ethical concerns associated with embryonic $\mathrm{SC}$, purification of SC cultures, the optimal timing and site of transplantation, in-vitro production of sufficient neural stem cells for transplantation that retain the ability to differentiate into mature cells, and long-term tracking of transplanted cells in humans. Additional obstacles to their therapeutic use include optimizing an effective delivery system, overcoming rejection of foreign cells and the effects of SC survival after delivery. Some advances have recently been made to address some these concerns, including genetically engineered human neural stem cells that permit cell proliferation and differentiation in-vivo and in-vitro and incorporation of superparamagnetic iron oxide nanocomposites into SC that permit MRI tracking in-vivo without impacting their survival or ability to differentiate (Guzman et al 2007; Zhu et al 2006).

\section{Genetics}

A great deal of research has been devoted to the prognostication of TBI, with most studies focusing on easily identifiable factors, such as the Glasgow Coma Scale score, length of post-traumatic amnesia, and a host of other injury-related characteristics that only partially explain the variance in outcomes. This strongly suggests that other factors play a significant role in the severity of and recovery from TBI. It is becoming increasingly evident that individual genetic factors play an influential role in determining outcomes, with several possible genes emerging as candidates.

With the completion of the Human Genome Project, it is certain that research examining the genetic role in outcome prediction will grow tremendously in the near future, 
permitting not only a greater ability to predict recovery, but more importantly provide a means for medical science to both better understand the pathophysiological processes associated with TBI and a rationale to develop specific treatments that are individualized based on unique genotypes. Several variant forms of genes, known as polymorphisms, have been identified as potentially impacting the course of TBI, with many more likely to be identified in the near future. To date, genes identified as either likely or possibly contributing to TBI outcomes include apoE4 and apoE promoter genes, calcium channel subunit gene, the p53 gene, catechol-omethyltranserase gene, D2 receptor gene, and genes coding for the production and metabolism of the interleukins, hemeoxygenase-1 (HO-1), and angiotensin converting enzyme.

It is important to note that many studies examining genetic contributions to the course of TBI are limited by the very nature of genetic science. The frequency of specific phenotypes is dependent on many factors beyond any one individual gene or overall genotype, including but not limited to how race and environmental factors impact genetic expression. Also, although some well-known genetic disorders are inherited as a single gene, such as Huntington's chorea, most others are polygenetic, and the influence of any one isolated gene is relatively small, which will almost certainly pertain to TBI. Furthermore, some distinct genes are physically linked such that they are inherited together, despite each having a unique function. This is known as linkage disequilibrium (LD). This may result in inadvertently identifying the wrong gene as impacting TBI if it is in LD with the actual offending gene. Also, the modulating role a specific genotype will have following TBI will likely depend on the distinct pathology present (eg, hemorrhagic versus non-hemorrhagic). For these and other reasons, genetic studies need to be sufficiently powered and be validated once initial findings are reported (Diaz-Arrastia and Baxter 2006), with results interpreted cautiously.

\section{APOE}

APOE are genes that exist in 3 alleles, $\varepsilon 2, \varepsilon 3$, and $\varepsilon 4$. They code for variants of apolipoprotein $\mathrm{E}(\mathrm{apoE})$ that serve as lipid carrier proteins responsible for transporting and distributing lipids among cells in the central nervous system (Mahley 1988). The presence of the $\varepsilon 4$ allele has been associated with increased risk of several neurological diseases, including late onset familial and sporadic Alzheimer's disease (Corder et al 1993; Saunders et al 1993), stroke (McCarron et al 1999), amyloid angiopathy, and HIV-related dementia (Corder et al 1998). More recently, several investigators have associated it with either poorer outcomes after severe TBI as measured by the Glasgow Outcome Scale and impaired cognitive function (Friedman et al 1999; Jordan et al 1997; Sorbi et al 1995; Teasdale et al 1997) or a slower recovery after controlling for other covariates (Alexander et al 2007). The mechanism by which the $\varepsilon 4$ allele impacts outcomes is not certain, although it is speculated to adversely effect processes involved in cellular membrane maintenance and repair (Mahley 1988; Weisgraber et al 1994), calcium metabolism (Veinbergs et al 2002), neural plasticity (Mauch et al 2001; Nathan et al 1994), and increased amyloid plaque deposition (Nicoll et al 1995). Additional evidence suggests the presence of the $\varepsilon 4$ allele may increase the risk of posttraumatic seizures (Diaz-Arrastia et al 2003) and late onset Alzheimer's disease after TBI (Mayeux et al 1993; Mortimer et al 1985; Mortimer et al 1991), although there have been conflicting results regarding the latter (Fleminger et al 2003; Nathoo et al 2003; Teasdale et al 2005). These differences in the studies examining the incidence in Alzheimer's disease may be related to methodological issues or the interaction of APOE on other factors such as age, gender and race. More notably however, the impact of APOE $\varepsilon 4$ on outcomes after mild TBI is less definitive than in severe TBI, with several studies finding no long-term effect associated with its presence (Chamelian et al 2004; Liberman et al 2002; Ponsford et al 2007).

Expression of the APOE gene is influenced by the APOE promoter gene, which also exists as one of several polymorphisms that can either up or down regulate apoE production. Several polymorphisms in the promotor gene are thought to increase susceptibility to AD by increasing expression of APOE $\varepsilon 4$ and the deposition of beta amyloid protein (Jordan et al 1997). At least one of these variant promoter genes has been associated with poorer outcomes 6 months after TBI (Jordan et al 1997), although further confirmatory studies are needed.

\section{Genes affecting catecholamine function}

Catecholaminergic dysfunction is well documented following TBI, manifested by decreased circulating levels of dopamine, norepinephrine and epinephrine as well as alterations in cortical catecholaminergic receptors (McIntosh 1994; McIntosh et al 1998; Prasad et al 1992). The beneficial role of catecholamine administration in animals post-TBI has been well known for decades and to a lesser degree in humans (McAllister et al 2005). Several genes have been identified that regulate catecholamine metabolism, which exist in several polymorphisms that can potentially impact 
cognitive outcomes post TBI. Catechol-o-methyltransferase (COMT) codes for an enzyme that inactivates both dopamine and norepinephrine. It exists in 3 isoforms, (val/val, val/met and met/met), each causing either an increase or decrease in enzymatic activity resulting in various levels of either neurotransmitter.

The val/val polymorphism coding for COMT results in increased enzymatic activity causing decreased levels of dopamine and has been associated with impaired cognitive skills post-TBI compared to those without this variant (Flashman et al 2004; Jordan et al 1997; McAllister et al 2005). Research utilizing fMRI revealed differences in activation patterns during a working memory task depending on the presence or absence of the val allele in both control and TBI subjects, with additional differences in activation patterns resulting from administration of a dopaminergic agonist (McAllister et al 2004). Although this study was small and has yet to be replicated, it suggests that variations in COMT genotypes modulate not only the location of activation in the brain during a specific cognitive task, but also the action of administered pharmacological agents. If results of this study are replicated, it strongly suggests that the combination of genetics, advanced neuroimaging, and pharmacology may lead to more targeted treatments for specific individuals.

Catecholiminergic activity is also affected by the dopamine D2 receptor allele, which codes for a dopamine receptor. Various polymorphisms here result in either increased or decreased expression of dopamine receptors that may impact cognition. A reduction in expression resulting from a specific genotype has been associated with impaired cognitive performance after TBI, consistent with dopaminergic modulation of cognitive function (McAllister et al 2005).

\section{Genes affecting inflammation}

Interleukin IL- $1 \alpha$ and IL- $1 \beta$ are pro-inflammatory cytokines that are involved in the molecular response to injury, contributing to neuronal death (Rothwell 1999). They are encoded by genes that are usually in linkage dysequilibrium and include IL1A and IL1B. ILRA is a gene that codes for a receptor antagonist to IL- $1 \alpha$ and IL- $1 \beta$ that modulate inflammation. All of these genes have various isoforms, IL1A*1 and IL1A*2; IL1B*1 and IL1B*2; and ILRA*1 and ILRA*2. The presence of the IL1A*2 and IL1B*2 alleles has been associated with increased risk of developing myasthenia gravis, juvenile rheumatoid arthritis and Alzheimer's disease (Huang et al 1998; Jordan et al 1997; McDowell et al 1995; Nicoll et al 2000) in association with increased production of IL- $1 \alpha$ and IL-1 $\beta$. All of these genes are activated in response to TBI and depending on the specific polymorphisms present, appear to modulate neuronal death in distinct ways. For example, the ILRA*2 allele has been associated with increased incidence of both hemorrhagic contusions and subarachnoid hemorrhages post-TBI (Hadjigeorgiou et al 2005). Other inflammation-regulating genes have been identified, including those coding for interleukin-6 (Winter et al 2004), heme-oxygenase-1, angiotensin converting enzyme, which may also impact pathophysiology post TBI. The precise mechanism underlying this is unclear as inflammation plays a dual role following injury, contributing to both pathological injury and repair. However, by better delineating the processes involved in pathology and repair, including examining the role played by genetic polymorphisms and its impact on inflammation, interventions can be better developed in terms of individual specificity, timing and dosing of treatments.

\section{Growth factors}

Interest in central nervous system (CNS) growth factors is growing, particularly regarding brain-derived neurotrophic factor (BDNF) and peripheral vascular endothelial growth factor (VEGF), as they have been associated with neurogenesis in the hippocampus, recovery from injury and prevention of the effects of Alzheimer's disease. BDNF is a protein that plays a critical role in CNS development (Lewin 1996; Lindsay 1996) but is also involved in cerebral plasticity, growth, recovery from injury (Binder and Scharfman 2004) learning and memory. It also plays a role in the regulation of stress and depression by enhancing the effectiveness of antidepressant medications (Russo-Neustadt et al 2001) as well as processing its own antidepressant properties (Siuciak et al 1997). Levels of BDNF have been shown to increase in response to exercise (Hicks et al 1998), which has been correlated with improved learning. BDNF has been shown to impact favorably on axonal growth and neurogenesis (Boyd and Gordon 2002; de Groot et al 2006; Goldman 1998; Pencea et al 2001; Scharfman et al 2005), raising the possibility of utilizing it as a means to enhance recovery. However, exogenous BDNF results in down regulation of specific receptors that appears to block its effectiveness (Blaha et al 2000; Xu et al 2004). Therefore, it is likely that BDNF needs to be produced endogenously through exercise, in order for it to have a favorable impact on recovery.

VEGF has also been shown to be related to neurogenesis in the hippocampus, which has been associated with improved memory and learning in an animal model (Cao et al 2004). Similar to BDNF, VEGF levels increase in response to 
exercise and have been shown to improve cognition in rats in association with neurogenesis in the hippocampus. (During and Cao 2006; Yasuhara et al 2004). These preliminary studies suggest a potential role exercise induced production of neurotrophic factors may play in recovery of cognitive skills following TBI.

\section{Alternative and complementary treatments}

Alternative and complementary treatments are "therapies or diagnostic techniques that are not part of the current Western health care system" (McElligott et al 2006, p. 1061). They encompass a variety of approaches including herbal supplements, homeopathy, hyperbaric oxygen, EEG-based therapy, chiropractice, craniosacral therapy, arts and recreational therapies (such as dance, music, art, horticulture), and interventions of Asian origin such as mindfulness and meditation practice, Tai Chi Chuan, Ayurvedic medicine, and acupuncture. Integrative medicine is a medical approach that combines alternative and complementary treatments with traditional Western techniques and is becoming increasingly available throughout the US. Although empirical literature on alternative and complementary treatments for humans with TBI is sparse with many studies either insufficiently powered or poorly controlled, their widespread use and popularity in the general population and interest among brain injury clinicians demands further scientific investigation to better determine their future role (Laures and Shisler 2004; Murrey 2006; Tindle et al 2005; Winnick 2007).

The literature on herbal supplements following TBI is limited to commentaries and case studies with very few published empirical studies on their effectiveness, raising some concerns regarding their safety and interactions with other medications, particularly when used without physician supervision (Elovic and Zafonte 2001; Spinella and Eaton 2002). One double-blind, placebo-controlled study examined the use of homeopathic treatment in subjects with mild TBI with results indicating significant improvement and a medium size effect on self-reported functional disability and commonly reported TBI symptoms. It is important to note however that no research has been published in this area since 1999 (Chapman et al 1999).

Several studies have focused on hyperbaric oxygen therapy (HBO) in populations with severe TBI (Adamides et al 2006; Al-Waili et al 2005; Golden et al 2006; Hardy et al 2007; McDonagh et al 2003; Rockswold et al 1992, 2007; Shi et al 2006). Severe TBI often results in ischemia and anaerobic metabolism leading to a destructive chemical chain reaction at the cellular and mitochondrial level resulting in secondary brain injury or death (Rockswold et al 2007). HBO involves exposing the individual to pure oxygen in an environment with greater than normal atmospheric pressures. It appears to improve cerebral aerobic metabolism at a mitochondrial level (Daugherty et al 2004; Zhou et al 2007), although there is some debate as to whether this constitutes a promising area for intervention as concerns have been raised about oxygen toxicity and the lack of class I evidence supporting its efficacy (Adamides et al 2006; McDonagh et al 2003). Some literature suggests that HBO can decrease mortality and improve neuropsychological and functional outcomes after severe TBI but there is still insufficient evidence to recommend its use (Golden et al 2006; Hardy et al 2007; McDonagh et al 2003; McElligott et al 2006; Rockswold et al 2007). Current research is focusing on comparing the utility of $\mathrm{HBO}$ to that of normobaric hyperoxia, a less expensive and easier to administer alternative, and examining the mechanisms of action of HBO (Rockswold et al 2007).

The successful use of acupuncture for treating TBI-related pain, spasticity and altered level of consciousness has been reported in several studies (Donnellan 2006; Tamai et al 2007). In one randomized trial of 30 individuals in posttraumatic coma, 15 subjects received routine medical care combined with acupuncture and point injection therapy while 15 controls received only standard treatment (He et al 2005). Those in the acupuncture condition showed significantly more improvement than controls in language, motor and cranial nerve function. The results of another study comparing acupuncture to placebo in treating individuals with post-TBI facial paralysis using a randomized two group ABA design in 50 subjects revealed significant improvements in the acupuncture group as compared to the control group (Zhao 2003). The utility of another therapy of Asian origin, Tai Chi Chuan, has been studied in improving mood, cognition, and mobility (Gemmell and Leathem 2006; Shapira et al 2001). However, small sample sizes and inadequately controlled experimental design limit the conclusions that can be drawn from these studies.

Schoenberger et al (2002) examined the effectiveness of the Flexyx Neurotherapy System, which combines biofeedback and photic stimulation (using glasses with light emitting diodes) in an attempt to affect EEG patterns that are known to be associated with cognitive dysfunction after TBI. In a randomized wait-list control design of 12 subjects, significant improvements in depression, fatigue, memory and learning were found. Controlled studies with sufficient statistical power examining this approach may thus be warranted. 
Mindfulness-based therapy is a Buddhist meditation-based technique that utilizes breathing exercises, guided visualization and group discussion. Bédard et al (2003) examined the impact of a 12-week mindfulness-based approach to reduce stress and improve quality of life in individuals with TBI. It was modeled on Kabat-Zinn's mindfulness-based stress reduction program and Kolb's experiential learning cycle (Kabat-Zinn 1982; Kolb 1984, p. 724). It endeavored to "encourage a new way of thinking about disability and how to approach life to bring a sense of acceptance, allowing participants to move beyond limiting beliefs". The researchers used a pre-post design with drop-outs as controls and found improved quality of life scores on the SF-36. Given the success of such interventions in other contexts, further research on mindfulness using more rigorous research designs is warranted (Allen et al 2006).

Literature is limited on the impact of music therapy in persons with TBI suggesting a possible positive impact on mood, socialization, and awareness, with decreases in undesired behaviors such as inertia and psychomotor agitation (Baker et al 2005; Formisano et al 2001; Magee and Davidson 2002; Magee 2005; Nayak et al 2000; Wheeler et al 2003). However, the evidence is based on case reports and small, largely uncontrolled studies and is thus preliminary in nature, indicating the need for further investigation.

In sum, despite some promising early research, there is little empirical basis for or against recommending particular complementary and alternative treatments. Given the public interest in treatments of this kind, the extent to which they are already used, and their potential benefits and risks, further research is urgently needed. In addition to both short and long-term efficacy, additional questions regarding subject selection, dosing, timing of treatment and concurrent treatments will also need to be addressed.

\section{Cognitive remediation}

Cognitive remediation is a widely used approach to restoring function and implementing compensatory strategies after brain injury. These interventions fall into three broad categories: 1) process-specific remediation, which focuses on very targeted areas of cognitive functioning, such as attention; 2) functional skills training, which focuses on improving cognitive functions by improving performance in functional activities of daily life; and 3) metacognitive remediation, which focuses on self-monitoring and self-regulation through the use of "top-down" strategies for addressing a range of problems and life situations of varying complexity (Cicerone 2006). Systematic reviews of cognitive remediation research conducted between 1988 and 2002 have identified over 250 studies, including 46 well-designed, randomized, controlled trials examining remediation of deficits after TBI and stroke in multiple cognitive domains (Cicerone et al 2000, 2005). Cicerone et al (2005, p. 1689) concluded that existing studies provide "substantial evidence to support cognitive rehabilitation for people with TBI" and have generated practice recommendations based on this evidence. Furthermore, they recommended that future research focus on treatment and patient factors that optimize cognitive rehabilitation outcomes rather than merely addressing whether or not cognitive rehabilitation is effective (Cicerone et al 2005). This is especially relevant given the heterogeneity of individuals with TBI and their cognitive deficits.

Although some process-specific approaches are wellsupported by research data, there are practical and theoretical reasons to incorporate multiple treatments into more holistic, multimodal programs of research (Ben-Yishay et al 1985; Cicerone et al 2006; Gordon et al 2006; Kaschel et al 2002; Ownsworth and Mcfarland 1999; Sohlberg and Mateer 1987; Sohlberg et al 2000; Wilson 1997; Wilson et al 2005). These reasons include the multi-faceted nature of post-TBI deficits, the inter-dependence of cognitive functions and emotions, and the need to facilitate functional change in multiple domains. For example, Gordon et al (2006) have outlined a theoretically based model for the rehabilitation of executive dysfunction that draws on models of cerebral function and organization, cognitive behavioral theory, and learning theory. The intervention based on this model combines top-down and bottom-up approaches, including empirically-validated interventions for attention, problem solving, and emotional regulation. These are embedded in a day-treatment program that also uses "standard" cognitive rehabilitation approaches such as memory planners, psychoeducation groups, and social skills training. Despite the fact that theoretically-driven multimodal and holistic treatments of this kind represent a promising approach to addressing the complexity of post-TBI cognitive difficulties, very few randomized controlled trials have been conducted and their external validity is poor (Cicerone 2006; Ruff et al 1989; Salazar et al 2000). However, there is a growing body of evidence that supports the use of such approaches and their long-term benefits (Cicerone 2006; Cicerone et al 2004; Hashimoto et al 2006; High et al 2006; Malec 2001; Rath et al 2003; Sander et al 2001; Sarajuuri et al 2005). Several authors have pointed out that future research will need to focus on comparing the impact of targeted and multimodal holistic interventions and improving the sensitivity and 
specificity of outcome measurement in research of this kind (Cicerone 2006; Cicerone et al 2006; Gordon et al 2006).

Research on technologically driven cognitive rehabilitation interventions has examined the impact of a variety of assistive devices and services to provide cues and memory aids for individuals with brain injury and improve cognitive functioning through computerized remediation (Bergman 2003; Gorman et al 2003; Hart et al 2002; Kim et al 2000; Tam et al 2003; van den Broek et al 2000; Wilson et al 2005; Wright et al 2001a, b). For example, the NeuroPage system is an innovative approach that reduces everyday planning and memory problems in individuals with brain injury through the use of pagers to send pre-arranged cues to remind them of tasks that they need to do (eg, take medications or make lunch) (Wilson et al 2001, 2003, 2005). In well-designed randomized controlled trials, this simple approach was shown to significantly improve memory performance and reduce healthcare costs (Wilson et al 2001, 2005). However, most of the existing research is not of this caliber, and is composed of small, uncontrolled studies, and case reports (Bergman 2003; Gorman et al 2003; Kim et al 2000; van den Broek et al 2000; Wright et al 2001a, 2001b). Although there is evidence to suggest that many clinicians and individuals with TBI use or are interested in using newer electronic technologies for cognitive rehabilitation, the research literature has yet to explore the possibilities of these methods in any depth (Hart et al 2003; Hart et al 2004; O’Neil-Pirozzi et al 2004).

\section{Ecologically valid neuropsychological assessment}

Neuropsychology has begun to shift from a primary focus on diagnostic evaluations designed to identify neuropathological impairments in specific cognitive domains to greater emphasis on the consideration of the functional implications of neuropsychological test results and their relationship to an individual's performance of everyday tasks (Rabin et al 2007; Standen and Brown 2005). More recently, particularly in the rehabilitation of individuals with TBI, there has been interest in developing measures that assess functional abilities to more accurately assess performance in the "real world" (Chaytor and Schmitter-Edgecombe 2003; Long and Kibby 1995; Sbordone 1996; Troster 2000) Tests designed with ecological validity in mind, as opposed to traditional neuropsychological tests, may be more effective in determining the extent to which an intervention improves an individual's performance on everyday cognitive tasks. However, older neuropsychological tests that were designed to diagnose neuropathology are now used to make predictions about real world functioning, yet there is limited research on the ecological validity of these tests (Rabin et al 2007; Standen and Brown 2005).

More recently, several neuropsychological measures that have been designed with ecological validity as a primary consideration have made progress towards wider acceptance. Most of these measures have been developed in the United Kingdom or Canada. They include the Test of Everyday Attention (TEA) (Robertson et al 1994), the Behavioral Assessment of the Dysexecutive Syndrome (BADS) (Wilson et al 1996), the Rivermead Behavioral Memory Test (RBMT) (Wilson et al 1985), the Cambridge Test of Prospective Memory (CAMPROMPT) (Wilson et al 2004), and the Multiple Errands Test (MET) (Alderman et al 2003; Burgess et al 2006; Knight et al 2002; Shallice and Burgess 1991). They differ from traditional neuropsychological measures by focusing on identifying limitations in functional abilities rather than discriminating brain injured from healthy people or determining the etiology of brain dysfunction (Chaytor and Schmitter-Edgecombe 2003). However, there is tremendous variability in the everyday demands facing individuals with TBI and they may require very different skill sets. For example, the cognitive skills required of a teacher differ from those of a fireman or a banker. Therefore, most of these tests, particularly in the domain of executive functioning, lack specificity, even when they are sensitive to dysfunction (Cicerone et al 2006).

This change in focus of the purpose of neuropsychological evaluation is extremely relevant in rehabilitation, where the primary goal is treatment planning rather than determining the type and location of cerebral abnormalities. To ensure appropriate treatment, interventions are designed and tailored to the individual and the primary role of the neuropsychological evaluation is to assess the likely implications of the findings on the person's ability to carry out daily activities (Bennett 2001). This then guides the treatment team on the type of rehabilitation required and the degree of recovery that can reasonably be expected.

\section{Virtual reality}

Rapid advances in computer technology have led to the creation of multiple virtual reality (VR) applications which allow the user to interact with, and become immersed in, a computer-generated environment that simulates a real world environment (Chute 2002; Rizzo et al 1997). VR techniques can been used as a means to bridge the gap between diagnostic measurement tools and ability to function in 
natural environments by using computer-based interactive instruments to assess level of functioning in real life simulations, thereby creating more ecologically valid and dynamic assessment and training. They also have the capacity to provide a consistent environment with the potential for infinite repetitions of the same assessment or training task while maintaining the flexibility to alter sensory presentations, task complexity, response requirements, and the nature and pattern of feedback in order to adapt to a user's unique impairments. Thus VR offers the potential to develop both neuropsychological assessment tools and treatment environments that can accurately determine cognitive and functional performance by precisely controlling complex stimulus presentation (Schultheis et al 2002).

$\mathrm{VR}$ is a relatively new approach in rehabilitation medicine, yet it offers considerable potential to achieve significant successes in assessment, treatment and improved outcome (Johnson et al 1998; Rose et al 2005) The technology is rapidly becoming more available and affordable for rehabilitation research and the clinical application allows flexibility for investigators and clinicians to tailor the system to particular interests or needs (Baumann et al 2003).

The simulation of real world activities can facilitate the evaluation of an individual's cognitive capacity and performance ability for tasks in their own natural environment. Additionally, VR tasks can provide a safe setting to assess skills that might be too risky in the real world (eg, driving). The individual's own fear of the reaction of others to faulty attempts in a natural environment are minimized, and limited resources that often make trips to a real environment difficult are easily addressed. In the virtual environment, people can go where they like even if they have mobility or balance problems. They can make mistakes without suffering the real, humiliating, or dangerous consequences of their errors (Standen and Brown 2005). VR technology can also be used for interventions, particularly when sensory, motor and cognitive consequences of brain injury combine to make environmental interaction difficult or dangerous. Interventions have been evaluated in the areas of exercise, yielding improvements in reaction times (Grealy et al 1999; Thornton et al 2005) and balance (Morganti et al 2007; Sveistrup et al 2003). In cases where the actual activity is too complex for an individual to perform, the VR world can be manipulated to break down the activity into multiple and progressively more difficult tasks, so that the person can learn in a safe realm. VR has been used in the area of rehabilitation to increase skills for independent living, enhance cognitive performance, and improve social skills.
As an assessment tool, VR environments can enhance the ecological validity of fMRI research. Typical fMRI experimental designs are often simple, contrived and devoid of real life context. While these basic designs are useful in mapping primary functional areas of the brain, they provide minimal views of the networked brain activity that must occur during real life situations when multiple functional areas are called upon to guide one's behavior. Pilot data from an fMRI study of memory for spatial navigation showed robust activation in multiple cortical regions expected to be involved in the task (Baumann et al 2003).

Additionally, assessment of executive functioning skills with the Multiple Errands Task has been developed in a VR format and was tested on five patients with executive dysfunction and five matched controls (McGeorge et al 2001). Those with impairments performed more poorly relative to controls on the real and virtual versions of the MET. In addition, there was a significant correlation between performance in the real and virtual task, providing a more discriminating method of assessing planning impairments than currently available on standardized neuropsychological tests.

VR environments have been used to examine simulated driving performance compared to on-road, cognitive, visualperceptual, and driving video test results, and have been found to be reliable and valid as a screening tool for assessing driving performance (Lengenfelder et al 2002; Schultheis et al 2007; Wald et al 2000; Wald and Liu 2001). Research continues to focus on establishing the reliability and validity of different driving simulators (Schultheis et al 2007; Wald et al 2000; Wald and Liu 2001). The next step will be to progress from evaluation to treatment that improves driving skill, much like VR simulators for pilots. VR environments have also been created to simulate tasks associated with cooking (Christiansen et al 1998; Zhang et al 2001, 2003) and shopping (Lee et al 2003). Stability of performance using the simulated virtual environment and appears to be a good predictor for real world performance.

Overall, virtual technology is less developed as a rehabilitative intervention than as a method of assessment (Standen and Brown 2005), but recent intervention studies are promising. Thus effective VR rehabilitation could be adapted for individuals to use in inpatient, outpatient and home care as a supplement or alternative to conventional therapy.

\section{Conclusions}

TBI is a common problem that causes widespread disability. Despite the enormity of the problem, few data exist regarding effective treatments beyond the very acute period. 
This is partially because there is insufficient understanding of both normal and impaired cerebral development and function and the factors that impact outcomes post-TBI. Advances in the realms of understanding cerebral physiology and function, assessment tools, growth factors and genetics in addition to the development of innovative research designs will provide the necessary framework to better develop treatments that are specific to individuals with unique injury characteristics and genotypes. It is almost a certainty that any single future intervention will be insufficient to address the multitude of physical, behavioral and cognitive problems caused by TBI. Therefore, as new technologies and treatments evolve, it will likely become evident that various treatment "cocktails" will emerge that combine approaches to assessments and treatment that will result in improved recovery by tailoring specific approaches to individuals with TBI.

\section{Acknowledgments}

The authors would like to thank Guido Mascialino, Angela $\mathrm{Yi}$, and Stacy Belkonen for their assistance in the preparation of this manuscript.

\section{Disclosures}

None of the authors has any conflicts of interest to declare.

\section{References}

Adamides AA, Winter CD, Lewis PM, et al. 2006. Current controversies in the management of patients with severe traumatic brain injury. $A N Z$ J Surg, 76:163-74.

Alderman N, Burgess PW, Knight C, et al. 2003. Ecological validity of a simplified version of the multiple errands shopping test. $J$ Int Neuropsychol Soc, 9:31-44.

Alexander S, Kerr ME, Kim Y, et al. 2007. Apolipoprotein E4 allele presence and functional outcome after severe traumatic brain injury. J Neurotrauma, 24:790-7.

Allen NB, Chambers R, Knight W. Melbourne Academic Mindfulness Interest Group. 2006. Mindfulness-based psychotherapies: a review of conceptual foundations, empirical evidence and practical considerations. Aust N Z J Psychiatry, 40:285-94.

Allister M, TW MD, BC F. 2004. Differential effect of COMT allele status on frontal activation associated with a dopaminergic agonist. $J$ Neuropsychiatry Clin Neurosci, 16:240.

Al-Waili NS, Butler GJ, Beale J, et al. 2005. Hyperbaric oxygen in the treatment of patients with cerebral stroke, brain trauma, and neurologic disease. Adv Ther, 22:659-78.

Baker F, Wigram T, Gold C. 2005. The effects of a song-singing programme on the affective speaking intonation of people with traumatic brain injury. Brain Inj, 19:519-28.

Bang OY, Lee JS, Lee PH, et al. 2005. Autologous mesenchymal stem cell transplantation in stroke patients. Ann Neurol, 57:874-82.

Baumann S, NeffC, Fetzick S, et al. 2003. A virtual reality system for neurobehavioral and functional MRI studies. Cyberpsychol Behav, 6:259-66.

Bedard M, Felteau M, Mazmanian D, et al. 2003. Pilot evaluation of a mindfulness-based intervention to improve quality of life among individuals who sustained traumatic brain injuries. Disabil Rehabil, 25:722-31.
Bennett TL. 2001. Neuropsychological evaluation in rehabilitation planning and evaluation of functional skills. Arch Clin Neuropsychol, 16:237-53.

Benson RR, Meda SA, Vasudevan S, et al. 2007. Global white matter analysis of diffusion tensor images is predictive of injury severity in traumatic brain injury. J Neurotrauma, 24:446-59.

Ben-Yishay Y, Rattock J, Lakin P, et al. 1985. Neuropsychological rehabilitation: quest for a holistic approach. Semin Neurol, 5:252-8.

Berardelli A, Inghilleri M, Rothwell JC, et al. 1998. Facilitation of muscle evoked responses after repetitive cortical stimulation in man. Exp Brain Res, 122:79-84.

Bergman MM. 2003. The essential steps cognitive orthotic. NeuroRehabilitation, 18:31-46.

Binder DK, Scharfman HE. 2004. Brain-derived neurotrophic factor. Growth Factors, 22:123-31.

Blaha GR, Raghupathi R, Saatman KE, et al. 2000. Brain-derived neurotrophic factor administration after traumatic brain injury in the rat does not protect against behavioral or histological deficits. Neuroscience, 99:483-93.

Boyd JG, Gordon T. 2002. A dose-dependent facilitation and inhibition of peripheral nerve regeneration by brain-derived neurotrophic factor. Eur J Neurosci, 15:613-26.

Burgess PW, Alderman N, Forbes C, et al. 2006. The case for the development and use of "ecologically valid" measures of executive function in experimental and clinical neuropsychology. $J$ Int Neuropsychol Soc, 12:194-209

Butefisch CM, Khurana V, Kopylev L, and Cohen LG. 2004. Enhancing encoding of a motor memory in the primary motor cortex by cortical stimulation. J Neurophysiol, 91:2110-6.

Cao L, Jiao X, Zuzga DS, Liu Y, Fong DM, Young D, et al. 2004. VEGF links hippocampal activity with neurogenesis, learning and memory. Nat Genet, 36:827-35.

Caramia MD, Iani C, Bernardi G. 1996. Cerebral plasticity after stroke as revealed by ipsilateral responses to magnetic stimulation. Neuroreport, 7:1756-60.

Chamelian L, Reis M, Feinstein A. 2004. Six-month recovery from mild to moderate traumatic brain injury: the role of APOE-epsilon4 allele. Brain, 127:2621-8.

Chapman EH, Weintraub RJ, Milburn MA, et al. 1999. Homeopathic treatment of mild traumatic brain injury:A randomized, double-blind, placebo-controlled clinical trial. J Head Trauma Rehabil, 14:521-42.

Chaytor N, Schmitter-Edgecombe M. 2003. The ecological validity of neuropsychological tests:A review of the literature on everyday cognitive skills. Neuropsychol Rev, 13:181-97.

Chen J, Li Y, Wang L, et al. 2001. Therapeutic benefit of intravenous administration of bone marrow stromal cells after cerebral ischemia in rats. Stroke, 32:1005-11.

Chen R, Classen J, Gerloff C, et al. 1997. Depression of motor cortex excitability by low-frequency transcranial magnetic stimulation. Neurology, 48:1398-403.

Christiansen C, Abreu B, Ottenbacher K, et al. 1998. Task performance in virtual environments used for cognitive rehabilitation after traumatic brain injury. Arch Phys Med Rehabil, 79:888-92.

Chute DL. 2002. Neuropsychological technologies in rehabilitation. J Head Trauma Rehabil, 17:369-77.

Cicerone K. 2006. Cognitive rehabilitation. In: Zasler ND, Katz D, Zafonte R (eds). Neurorehabilitation of traumatic brain injury. New York: Demos Publishers. pp. 765-77.

Cicerone K, Levin H, Malec J, et al. 2006. Cognitive rehabilitation interventions for executive function:Moving from bench to bedside in patients with traumatic brain injury. J Cogn Neurosci, 18:1212-22.

Cicerone KD, Dahlberg C, Kalmar K, et al. 2000. Evidence-based cognitive rehabilitation:Recommendations for clinical practice. Arch Phys Med Rehabil, 81:1596-615.

Cicerone KD, Dahlberg C, Malec JF, et al. 2005. Evidence-based cognitive rehabilitation: updated review of the literature from 1998 through 2002. Arch Phys Med Rehabil, 86:1681-92. 
Cicerone KD, Mott T, Azulay J, et al. 2004. Community integration and satisfaction with functioning after intensive cognitive rehabilitation for traumatic brain injury. Arch Phys Med Rehabil, 85:943-50.

Cohen BA, Inglese M, Rusinek H, et al. 2007. Proton MR spectroscopy and MRI-volumetry in mild traumatic brain injury. AJNR Am JNeuroradiol, 28:907-13.

Corder EH, Robertson K, Lannfelt L, et al. 1998. HIV-infected subjects with the E4 allele for APOE have excess dementia and peripheral neuropathy. Nat Med, 4:1182-4.

Corder EH, Saunders AM, Strittmatter WJ, et al. 1993. Gene dose of apolipoprotein E type 4 allele and the risk of alzheimer's disease in late onset families. Science, 261:921-3.

Daugherty WP, Levasseur JE, Sun D, et al. 2004. Effects of hyperbaric oxygen therapy on cerebral oxygenation and mitochondrial function following moderate lateral fluid-percussion injury in rats. J Neurosurg, 101:499-504.

de Groot DM, Coenen AJ, Verhofstad A, et al. 2006. In vivo induction of glial cell proliferation and axonal outgrowth and myelination by brainderived neurotrophic factor. Mol Endocrinol, 20:2987-98.

Demougeot C, Garnier P, Mossiat C, et al. 2001. N-acetylaspartate, a marker of both cellular dysfunction and neuronal loss:Its relevance to studies of acute brain injury. $J$ Neurochem, 77:408-15.

Diaz-Arrastia R, Baxter VK. 2006. Genetic factors in outcome after traumatic brain injury: What the human genome project can teach us about brain trauma. J Head Trauma Rehabil, 21:361-74.

Diaz-Arrastia R, Gong Y, Fair S, et al. 2003. Increased risk of late posttraumatic seizures associated with inheritance of APOE epsilon4 allele. Arch Neurol, 60:818-22.

Diaz-Marchan PG, Hayman LA, Carrier DA, et al. 1996. Computed tomography of closed head injury. In: Narayan RK, Wilburger JE, Povlishock JT (eds). Neurotrauma New York: McGraw-Hill. pp. 137, 138-49.

Donnellan CP. 2006. Acupuncture for central pain affecting the ribcage following traumatic brain injury and rib fractures - a case report. Acupunct Med, 24:129-33.

During MJ, Cao L. 2006. VEGF, a mediator of the effect of experience on hippocampal neurogenesis. Curr Alzheimer Res, 3:29-33.

Elovic EP, Zafonte RD. 2001. Ginkgo biloba: applications in traumatic brain injury. J Head Trauma Rehabil, 16:603-7.

Flashman L, Saykin A, Rhodes C, et al. 2004. Effect of COMT Val/Met genotype on frontal lobe functioning in traumatic brain injury. $J$ Neuropsychiatry Clin Neurosci, 16:238-9.

Fleminger S, Oliver DL, Lovestone S, et al. 2003. Head injury as a risk factor for alzheimer's disease: the evidence 10 years on; a partial replication. J Neurol Neurosurg Psychiatry, 74:857-62.

Floel A, Cohen LG. 2007. Contribution of noninvasive cortical stimulation to the study of memory functions. Brain Res Rev, 53:250-9.

Formisano R, Vinicola V, Penta F, et al. 2001. Active music therapy in the rehabilitation of severe brain injured patients during coma recovery. Ann Ist Super Sanita, 37:627-30.

Fregni F, Marcolin MA, Myczkowski M, et al. 2006. Predictors of antidepressant response in clinical trials of transcranial magnetic stimulation. Int J Neuropsychopharmacol, 9:641-54.

Friedman G, Froom P, Sazbon L, et al. 1999. Apolipoprotein E-e4 genotpe predicts a poor outcome in survivors of traumatic brain injury. Neurology, 52:244-8.

Garbuzova-Davis S, Willing AE, Saporta S, et al. 2006. Novel cell therapy approaches for brain repair. Prog Brain Res, 157:207-22.

Garnett MR, Blamire AM, Corkill RG, et al. 2000. Early proton magnetic resonance spectroscopy in normal-appearing brain correlates with outcome in patients following traumatic brain injury. Brain, 123:2046-54.

Gemmell C, Leathem JM. 2006. A study investigating the effects of tai chi chuan: individuals with traumatic brain injury compared to controls. Brain Inj, 20:151-6.

Golden Z, Golden CJ, Neubauer RA. 2006. Improving neuropsychological function after chronic brain injury with hyperbaric oxygen. Disabil Rehabil, 28:1379-86.
Goldman SA. 1998. Adult neurogenesis: from canaries to the clinic. $J$ Neurobiol, 36:267-86.

Gordon WA, Cantor J, Ashman T, et al. 2006. Treatment of post-TBI executive dysfunction: application of theory to clinical practice. $J$ Head Trauma Rehabil, 21:156-67.

Gordon WA, Zafonte R, Cicerone K, et al. 2006. Traumatic brain injury rehabilitation:State of the science. Am J Phys Med Rehabil, 85:343-82.

Gorman P, Dayle R, Hood CA, et al. 2003. Effectiveness of the ISAAC cognitive prosthetic system for improving rehabilitation outcomes with neurofunctional impairment. NeuroRehabilitation, 18:57-67.

Grealy MA, Johnson DA, Rushton SK. 1999. Improving cognitive function after brain injury: the use of exercise and virtual reality. Arch Phys Med Rehabil, 80:661-7.

Grunhaus L, Schreiber S, Dolberg OT, et al. 2003. A randomized controlled comparison of electroconvulsive therapy and repetitive transcranial magnetic stimulation in severe and resistant nonpsychotic major depression. Biol Psychiatry, 53:324-31.

Guzman R, Uchida N, Bliss TM, et al. 2007. Long-term monitoring of transplanted human neural stem cells in developmental and pathological contexts with MRI. Proc Natl Acad Sci USA, 104:10211-6.

Hadjigeorgiou GM, Paterakis K, Dardiotis E, et al. 2005. IL-1RN and IL-1B gene polymorphisms and cerebral hemorrhagic events after traumatic brain injury. Neurology, 65:1077-82.

Hardy P, Johnston KM, De Beaumont L, et al. 2007. Pilot case study of the therapeutic potential of hyperbaric oxygen therapy on chronic brain injury. J Neurol Sci, 253:94-105.

Hart T, Buchhofer R, Vaccaro M. 2004. Portable electronic devices as memory and organizational aids after traumatic brain injury: a consumer survey study. J Head Trauma Rehabil, 19:351-65.

Hart T, Hawkey K, Whyte J. 2002. Use of a portable voice organizer to remember therapy goals in traumatic brain injury rehabilitation: a within-subjects trial. J Head Trauma Rehabil, 17:556-70.

Hart T, O’Neil-Pirozzi T, Morita C. 2003. Clinician expectations for portable electronic devices as cognitive-behavioural orthoses in traumatic brain injury rehabilitation. Brain Inj, 17:401-11.

Hashimoto K, Okamoto T, Watanabe S, et al. 2006. Effectiveness of a comprehensive day treatment program for rehabilitation of patients with acquired brain injury in japan. $J$ Rehabil Med, 38:20-5.

He J, Wu B, Zhang Y. 2005. Acupuncture treatment for 15 cases of posttraumatic coma. J Tradit Chin Med, 25:171-3.

Hicks RR, Boggs A, Leider D, et al. 1998. Effects of exercise following lateral fluid percussion brain injury in rats. Restor Neurol Neurosci, $12: 41-7$.

High WM Jr, Roebuck-Spencer T, Sander AM, et al. 2006. Early versus later admission to postacute rehabilitation: impact on functional outcome after traumatic brain injury. Arch Phys Med Rehabil, 87:334-42.

Huang D, Pirskanen R, Hjelmstrom P, Lefvert AK. 1998. Polymorphisms in IL-1beta and IL-1 receptor antagonist genes are associated with myasthenia gravis. J Neuroimmunol, 81:76-81.

Huisman TA, Schwamm LH, Schaefer PW, et al. 2004. Diffusion tensor imaging as potential biomarker of white matter injury in diffuse axonal injury. AJNR Am J Neuroradiol, 25:370-6.

Hummel F, Celnik P, Giraux P, et al. 2005. Effects of non-invasive cortical stimulation on skilled motor function in chronic stroke. Brain, 128:490-9.

Irani F, Platek SM, Bunce S, et al. 2007. Functional near infrared spectroscopy (fNIRS): an emerging neuroimaging technology with important applications for the study of brain disorders. Clin Neuropsychol, 21:9-37.

Jeong SW, Chu K, Jung KH, et al. 2003. Human neural stem cell transplantation promotes functional recovery in rats with experimental intracerebral hemorrhage. Stroke, 34:2258-63.

Johnson DA, Rose FD, Rushton SK, et al. 1998. Virtual reality:A new prosthesis for brain injury rehabilitation. Scott Med J, 43:81-3.

Jordan BD, Relkin NR, Ravdin LD, et al. 1997. Apolipoprotein E epsilon4 associated with chronic traumatic brain injury in boxing. JAMA, 278:136-40 
Kabat-Zinn J. 1982. An outpatient program in behavioral medicine for chronic pain patients based on the practice of mindfulness meditation: theoretical considerations and preliminary results. Gen Hosp Psychiatry, 4:33-47.

Kaschel R, Della Sala S, Cantagallo A, et al. 2002. Imagery mnemonics for the rehabilitation of memory: a randomised group controlled trial. Neuropsychol Rehabil, 12:127-53.

Khedr EM, Ahmed MA, Fathy N, et al. 2005. Therapeutic trial of repetitive transcranial magnetic stimulation after acute ischemic stroke. Neurology, 65:466-8.

Kim HJ, Burke DT, Dowds MM Jr, et al. 2000. Electronic memory aids for outpatient brain injury:Follow-up findings. Brain Inj, 14:187-96.

Kim SU. 2007. Genetically engineered human neural stem cells for brain repair in neurological diseases. Brain Dev, 29:193-201.

Knight C, Alderman N, Burgess PW. 2002. Development of a simplified version of the multiple errands test for use in hospital settings. Neuropsychol Rehabil, 12:231.

Kolb D. 1984. Experiential learning: experience as the source of learning and development. Englewood Cliffs, NJ:Prentice-Hall.

Kondziolka D, Wechsler L, Goldstein S, et al. 2000. Transplantation of cultured human neuronal cells for patients with stroke. Neurology, 55:565-9.

Krause JF, Arthur DL. 1999. Incidence and prevalence of, and cost associated with traumatic brain injury. In: Rosenthal M, Griffith ER, Bond MR, et al. (eds). Rehabilitation of the adult and child with traumatic brain injury 3rd ed. Philadelphia: F.A. Davis Company. pp. 3-18.

Langlois JA, Rutland-Brown W, Thomas KE. 2004. Traumatic brain injury in the united states: emergency department visits, hospitalizations, and deaths. Atlanta, GA:Centers for Disease Control and Prevention, National Center for Injury Prevention and Control.

Laures J, Shisler R. 2004. Complementary and alternative medical approaches to treating adult neurogenic communication disorders: a review. Disabil Rehabil, 26:315-25.

Lee HJ, Kim KS, Kim EJ, et al. 2007. Brain transplantation of immortalized human neural stem cells promotes functional recovery in mouse intracerebral hemorrhage stroke model. Stem Cells, 25:1204-12.

Lee JH, Ku J, Cho W, et al. 2003. A virtual reality system for the assessment and rehabilitation of the activities of daily living. Cyberpsychol Behav, 6:383-8.

Lengenfelder J, Schultheis MT, Al-Shihabi T, et al. 2002. Divided attention and driving:A pilot study using virtual reality technology. J Head Trauma Rehabil, 17:26-37.

Lewin GR. 1996. Neurotrophins and the specification of neuronal phenotype. Philos Trans R Soc Lond B Biol Sci, 351:405-11.

Lewine JD, Davis JT, Bigler ED, et al. 2007. Objective documentation of traumatic brain injury subsequent to mild head injury: multimodal brain imaging with MEG, SPECT, and MRI. J Head Trauma Rehabil, 22:141-55.

Li Y, Chen J, Chen XG, et al. 2002. Human marrow stromal cell therapy for stroke in rat:Neurotrophins and functional recovery. Neurology, 59:514-23.

Liberman JN, Stewart WF, Wesnes K, et al. 2002. Apolipoprotein E epsilon 4 and short-term recovery from predominantly mild brain injury. Neurology, 58:1038-44.

Lindsay RM. 1996. Role of neurotrophins and trk receptors in the development and maintenance of sensory neurons: an overview. Philos Trans $R$ Soc Lond B Biol Sci, 351:365-73.

Long CJ, Kibby MY. 1995. Ecological validity of neuropsychological tests: A look at neuropsychology's past and the impact that ecological issues may have on its future. Advances in Medical Psychotherapy, 8:59-78.

Mac Donald CL, Dikranian K, Song SK, Bayly PV, Holtzman DM, and Brody DL. 2007. Detection of traumatic axonal injury with diffusion tensor imaging in a mouse model of traumatic brain injury. Exp Neurol, 205:116-31.

Magee WL. 2005. Music therapy with patients in low awareness states: Approaches to assessment and treatment in multidisciplinary care. Neuropsychol Rehabil, 15:522-36.
Magee WL, Davidson JW. 2002. The effect of music therapy on mood states in neurological patients:A pilot study. J Music Ther, 39:20-9.

Mahley RW. 1988. Apolipoprotein E: cholesterol transport with expanding role in cell biology. Science, 240(4852):622-30.

Malec JF. 2001. Impact of comprehensive day treatment on societal participation for persons with acquired brain injury. Arch Phys Med Rehabil, 82:885-95.

Marino S, Zei E, Battaglini M, et al. 2007. Acute metabolic brain changes following traumatic brain injury and their relevance to clinical severity and outcome. J Neurol Neurosurg Psychiatry, 78:501-7.

Mauch DH, Nagler K, Schumacher S, et al. 2001. CNS synaptogenesis promoted by glia-derived cholesterol. Science, 294:1354-7.

Mayeux R, Ottman R, Tang MX, et al. 1993. Genetic susceptibility and head injury as risk factors for Alzheimer's disease among communitydwelling elderly persons and their first-degree relatives. Ann Neurol, 33:494-501.

McAllister TW, Rhodes CH, Flashman LA, et al. 2005. Effect of the dopamine D2 receptor T allele on response latency after mild traumatic brain injury. Am J Psychiatry, 162:1749-51.

McCarron MO, De Long D, Alberts MJ. 1999. APOE genotype as a risk factor for ischemic cerebrovascualr disease. Neurology, 53:1308-11.

McDonagh M, Carson S, Ash J, et al. 2003. Hyperbaric oxygen therapy for brain injury, cerebral palsy, and stroke. Evid Rep Technol Assess (Summ), 85:1-6.

McDowell TL, Symons JA, Ploski R, et al. 1995. A genetic association between juvenile rheumatoid arthritis and a novel interleukin-1 alpha polymorphism. Arthritis Rheum, 38:221-8.

McElligott J, David AM, Hecht JS, et al. 2007. Complementary and alternative medicine. In: Zasler ND, Katz DI, Zafonte RD (eds). Brain injury medicine: principles and practice. New York:Demos. pp. 1061,1062-82.

McElligott J, Davis AM, Hecht JS, et al. 2006. Complementary and alternative medicine. In: Zasler ND, Katz DI, Zafonte RD (eds). Brain injury medicine: principles and practice. New York: Demos Medical Publishing. pp. 1061-84.

McGeorge P, Phillips LH, Crawford JR, et al. 2001. Using virtual environments in the assessment of executive dysfunction. Presence: Teleoperators and Virtual Environments, 10:375-83.

McIntosh TK. 1994. Neurochemical sequelae of traumatic brain injury: Therapeutic implications. Cerebrovasc Brain Metab Rev, 6:109-62.

McIntosh TK, Juhler M, Wieloch T. 1998. Novel pharmacologic strategies in the treatment of experimental traumatic brain injury: 1998 . J Neurotrauma, 15:731-69.

McNamara B, Ray JL, Arthurs OJ, et al. 2001. Transcranial magnetic stimulation for depression and other psychiatric disorders. Psychol Med, 31:1141-6.

Morganti F, Gaggioli A, Strambi L, et al. 2007. A virtual reality extended neuropsychological assessment for topographical disorientation: A feasibility study. J Neuroengineering Rehabil, 4:26.

Mortimer JA, French LR, Hutton JT, et al. 1985. Head injury as a risk factor for alzheimer's disease. Neurology, 35:264-7.

Mortimer JA, van Duijn CM, Chandra V, et al. 1991. Head trauma as a risk factor for alzheimer's disease:A collaborative re-analysis of casecontrol studies. EURODEM risk factors research group. Int J Epidemiol, 20(Suppl 2):S28-35.

Muellbacher W, Ziemann U, Boroojerdi B, et al. 2000. Effects of lowfrequency transcranial magnetic stimulation on motor excitability and basic motor behavior. Clin Neurophysiol, 111:1002-7.

Murrey GJ. 2006. Alternate therapies in the treatment of brain injury and neurobehavioral disorders: a practical guide 1st ed. Binghamton, NY: Haworth Press.

Nakayama N, Okumura A, Shinoda J, et al. 2006. Evidence for white matter disruption in traumatic brain injury without macroscopic lesions. J Neurol Neurosurg Psychiatry, 77:850-5.

Nathan BP, Bellosta S, Sanan DA, et al. 1994. Differential effects of apolipoproteins E3 and E4 on neuronal growth in vitro. Science, 264:850-2. 
Nathoo N, Chetry R, van Dellen JR, et al. 2003. Apolipoprotein E polymorphism and outcome after closed traumatic brain injury: influence of ethnic and regional differences. J Neurosurg, 98:302-6.

Nayak S, Wheeler B, Shiflett S, et al. 2000. Effect of music therapy on mood and social interaction among individuals with acute traumatic brain injury and stroke. Rehabil Psychol, 45:274-83.

Netz J, Lammers T, Homberg V. 1997. Reorganization of motor output in the non-affected hemisphere after stroke. Brain, 120:1579-86.

Newcombe VF, Williams GB, Nortje J, et al. 2007. Analysis of acute traumatic axonal injury using diffusion tensor imaging. $\mathrm{Br} J$ Neurosurg, 21:340-8.

Nicoll JA, Mrak RE, Graham DI, et al. 2000. Association of interleukin-1 gene polymorphisms with alzheimer's disease. Ann Neurol, 47:365-8.

Nicoll JA, Roberts GW, Graham DI. 1995. Apolipoprotein E epsilon 4 allele is associated with deposition of amyloid beta-protein following head injury. Nat Med, 1:135-7.

Obrig H, Wenzel R, Kohl M, et al. 2000. Near-infrared spectroscopy: does it function in functional activation studies of the adult brain? Int $J$ Psychophysiol, 35:125-42.

Okamoto M, Dan H, Shimizu K, et al. 2004. Multimodal assessment of cortical activation during apple peeling by NIRS and fMRI. Neuroimage, 21:1275-88.

O’Neil-Pirozzi TM, Kendrick H, Goldstein R, et al. 2004. Clinician influences on use of portable electronic memory devices in traumatic brain injury rehabilitation. Brain Inj, 18:179-89.

Ownsworth TL, Mcfarland K. 1999. Memory remediation in long-term acquired brain injury: two approaches in diary training. Brain Inj, 13:605-26.

Peinemann A, Reimer B, Loer C, et al. 2004. Long-lasting increase in corticospinal excitability after 1800 pulses of subthreshold $5 \mathrm{hz}$ repetitive TMS to the primary motor cortex. Clin Neurophysiol, 115:1519-26.

Pencea V, Bingaman KD, Wiegand SJ, et al. 2001. Infusion of brain-derived neurotrophic factor into the lateral ventricle of the adult rat leads to new neurons in the parenchyma of the striatum, septum, thalamus, and hypothalamus. J Neurosci, 21:6706-17.

Ponsford J, Rudzki D, Bailey K, et al. 2007. Impact of apolipoprotein gene on cognitive impairment and recovery after traumatic brain injury. Neurology, 68:619-20.

Prasad MR, Tzigaret CM, Smith D, et al. 1992. Decreased alpha 1-adrenergic receptors after experimental brain injury. J Neurotrauma, 9:269-79.

Rabin LA, Burton LA, Barr WB. 2007. Utilization rates of ecologically oriented instruments among clinical neuropsychologists. Clin Neuropsychol, 21:727-43.

Rath JF, Simon D, Langenbahn DM, et al. 2003. Group treatment of problem-solving deficits in outpatients with traumatic brain injury: a randomised outcome study. Neuropsychol Rehabil, 13:461-88.

Reynolds BA, Weiss S. 1992. Generation of neurons and astrocytes from isolated cells of the adult mammalian central nervous system. Science, 255:1707-10.

Rizzo AA, Buckwalter JG, Neumann U. 1997. Virtual reality and cognitive rehabilitation:A brief review of the future. $J$ Head Trauma Rehabil, 12:1-15.

Robertson IH, Ward T, Ridgeway V, et al. 1994. The test of everyday attention manual.

Rockswold GL, Ford SE, Anderson DC, et al. 1992. Results of a prospective randomized trial for treatment of severely brain-injured patients with hyperbaric oxygen. J Neurosurg, 76:929-34.

Rockswold SB, Rockswold GL, Defillo A. 2007. Hyperbaric oxygen in traumatic brain injury. Neurol Res, 29:162-72.

Rose FD, Brooks BM, Rizzo AA. 2005. Virtual reality in brain damage rehabilitation: review. Cyberpsychol Behav, 8:241-62; discussion 263-71.

Rothwell NJ. 1999. Annual review prize lecture cytokines - killers in the brain? J Physiol, 514:3-17.

Ruff RM, Baser CA, Johnston JW, et al. 1989. Neuropsychological rehabilitation:An experimental study with head-injured patients. $J$ Head Trauma Rehabil, 4:20-36.
Russo-Neustadt A, Ha AR, Ramirez R, et al. 2001. Physical activity antidepressant treatment combination: impact on brain-derived neurotrophic factor and behavior in an animal model. Behav Brain Res, 120:87-95.

Salazar AM, Warden DL, Schwab K, Spector J, Braverman S, Walter J, et al. 2000. Cognitive rehabilitation for traumatic brain injury:A randomized trial. defense and veterans head injury program (DVHIP) study group. JAMA, 283:3075-81.

Sanberg PR, Willing AE, Sanberg C, et al. 2004. Different functional recovery and neurostructural repair of the stroke brain produced by volume-reduced and mononuclear fractioned human umbilical cord blood. Abstract Viewer/Itinerary Planner. Society for Neuroscience, Washington, DC.

Sander AM, Roebuck TM, Struchen MA, et al. 2001. Long-term maintenance of gains obtained in postacute rehabilitation by persons with traumatic brain injury. J Head Trauma Rehabil, 16:356-73.

Sarajuuri JM, Kaipio ML, Koskinen SK, et al. 2005. Outcome of a comprehensive neurorehabilitation program for patients with traumatic brain injury. Arch Phys Med Rehabil, 86:2296-302.

Saunders AM, Strittmatter WJ, Schmechel D, et al. 1993. Association of apolipoprotein E allele epsilon 4 with late-onset familial and sporadic alzheimer's disease. Neurology, 43:1467-72.

Savitz SI, Dinsmore JH, Wechsler LR, et al. 2004. Cell therapy for stroke. NeuroRx, 1:406-14.

Sbordone RJ. 1996. Ecological validity: some critical issues for the neuropsychologist. In: Sbordone RJ, Long CJ (eds). Ecological validity of neuropsychological testingBoca Raton, FL: St. Lucie Press. pp. 15.

Scharfman H, Goodman J, Macleod A, et al. 2005. Increased neurogenesis and the ectopic granule cells after intrahippocampal BDNF infusion in adult rats. Exp Neurol, 192:348-56.

Schoenberger NE, Shif SC, Esty ML, et al. 2001. Flexyx neurotherapy system in the treatment of traumatic brain injury:An initial evaluation. J Head Trauma Rehabil, 16:260-74.

Schultheis MT, Himelstein J, Rizzo AA. 2002. Virtual reality and neuropsychology: upgrading the current tools. J Head Trauma Rehabil, 17:378-94.

Schultheis MT, Rebimbas J, Mourant R, et al. 2007. Examining the usability of a virtual reality driving simulator. Assist Technol, 19:1-8; quiz 9-10.

Shallice T, Burgess PW. 1991. Deficits in strategy application following frontal lobe damage in man. Brain, 114:727-41.

Shapira MY, Chelouche M, Yanai R, et al. 2001. Tai chi chuan practice as a tool for rehabilitation of severe head trauma: 3 case reports. Arch Phys Med Rehabil, 82:1283-5.

Shi XY, Tang ZQ, Sun D, et al. 2006. Evaluation of hyperbaric oxygen treatment of neuropsychiatric disorders following traumatic brain injury. Chin Med J (Engl), 119:1978-82.

Shutter L, Tong KA, Holshouser BA. 2004. Proton MRS in acute traumatic brain injury:Role for glutamate/glutamine and choline for outcome prediction. J Neurotrauma, 21:1693-705.

Siebner HR, Rothwell J. 2003. Transcranial magnetic stimulation:New insights into representational cortical plasticity. Exp Brain Res, 148:1-16.

Signoretti S, Marmarou A, Fatouros P, et al. 2002. Application of chemical shift imaging for measurement of NAA in head injured patients. Acta Neurochir Suppl, 81:373-5.

Siuciak JA, Lewis DR, Wiegand SJ, et al. 1997. Antidepressant-like effect of brain-derived neurotrophic factor (BDNF). Pharmacol Biochem Behav, 56:131-7.

Sohlberg MM, Mateer CA. 1987. Effectiveness of an attention-training program. J Clin Exp Neuropsychol, 9:117-30.

Sohlberg MM, McLaughlin KA, Pavese A, et al. 2000. Evaluation of attention process training and brain injury education in persons with acquired brain injury. J Clin Exp Neuropsychol, 22:656-76.

Sorbi S, Nacmias B, Piacentini S, et al. 1995. ApoE as a prognostic factor for post-traumatic coma. Nat Med, 1:852. 
Spinella M, Eaton LA. 2002. Hypomania induced by herbal and pharmaceutical psychotropic medicines following mild traumatic brain injury. Brain Inj, 16:359-67.

Standen PJ, Brown DJ. 2005. Virtual reality in the rehabilitation of people with intellectual disabilities: review. Cyberpsychol Behav, 8:272-82; discussion 283-8.

Sveistrup H, McComas J, Thornton M, et al. 2003. Experimental studies of virtual reality-delivered compared to conventional exercise programs for rehabilitation. Cyberpsychol Behav, 6:245-9.

Tam SF, Man WK, Hui-Chan CW, et al. 2003. Evaluating the efficacy of tele-cognitive rehabilitation for functional performance in three case studies. Occup Ther Int, 10:20-38.

Tamai H, Yamaguchi T, Watanabe E, et al. 2007. Acupuncture treatment for a patient with diffuse axonal injury. Masui, 56:203-6.

Teasdale GM, Murray GD, Nicoll JA. 2005. The association between APOE epsilon4, age and outcome after head injury: a prospective cohort study. Brain, 128:2556-61.

Teasdale GM, Nicoll JA, Murray G, et al. 1997. Association of apolipoprotein E polymorphism with outcome after head injury. Lancet, 350:1069-71

Thornton M, Marshall S, McComas J, et al. 2005. Benefits of activity and virtual reality based balance exercise programmes for adults with traumatic brain injury: perceptions of participants and their caregivers. Brain Inj, 19:989-1000.

Thurman DJ, Alverson C, Dunn KA, et al. 1999. Traumatic brain injury in the united states:A public health perspective. J Head Trauma Rehabil, $14: 602-15$.

Tindle HA, Davis RB, Phillips RS, et al. 2005. Trends in use of complementary and alternative medicine by US adults: 1997-2002. Altern Ther Health Med, 11:42-9.

Troster AI. 2000. Clinical neuropsychology, functional neurosurgery, and restorative neurology in the next millennium:Beyond secondary outcome measures. Brain Cogn, 42:117-9.

Turton A, Wroe S, Trepte N, et al. 1996. Contralateral and ipsilateral EMG responses to transcranial magnetic stimulation during recovery of arm and hand function after stroke. Electroencephalogr Clin Neurophysiol, 101:316-28

van den Broek MD, Downes J, Johnson Z, et al. 2000. Evaluation of an electronic memory aid in the neuropsychological rehabilitation of prospective memory deficits. Brain Inj, 14:455-62.

Veinbergs I, Everson A, Sagara Y, et al. 2002. Neurotoxic effects of apolipoprotein E4 are mediated via dysregulation of calcium homeostasis. J Neurosci Res, 67:379-87.

Villringer A, Chance B. 1997. Non-invasive optical spectroscopy and imaging of human brain function. Trends Neurosci, 20:435-42.

Wald J, Liu L, Hirsekorn L, Taylar S. 2000. The use of virtual reality in the assessment of driving performance in persons with brain injury. Stud Health Technol Inform, 70:365-7.

Wald JL, Liu L, Reil S. 2000. Concurrent validity of a virtual reality driving assessment for persons with brain injury. CyberPsychol Behav, 3:643-54.

Wald J, Liu L. 2001. Psychometric properties of the driVR: a virtual reality driving assessment. Stud Health Technol Inform, 81:564-6.

Wassermann EM. 2002. Safety and side-effects of transcranial magnetic stimulation and repetitive transcranial magentic stimulation. In: A. Pacual-Leone, N. Davey, E. M. Wassermann, B. K. Puri and J. Rothwell (eds). Handbook of transcranial magnetic stimulationNew York:Hodder Arnold. pp. 39, 40-49.

Weisgraber KH, Roses AD, Strittmatter WJ. 1994. The role of apolipoprotein E in the nervous system. Curr Opin Lipidol, 5:110-6.

Wheeler B, Shiflett S, Nayak N. 2003. Effects of number of sessions and group or individual music therapy on the mood and behaviour of people who have had strokes or traumatic brain injury. Nordic Journal of Music Therapy, 12:139-51.
Wilson B, Alderman N, Burgess P, et al. 1996. Behavioural assessment of the dysexecutive syndrome. Bury St. Edmunds, England: Thames Valley Test Company.

Wilson BA, Cockburn J, Baddeley AD. 1985. The rivermead behavioural memory test manual. Suffolk: Thames Valley.

Wilson BA, Shiel A, Foley J, et al. 2004. Cambridge test of prospective memory. Bury St. Edmunds, England: Thames Valley Test Company.

Wilson BA. 1997. Cognitive rehabilitation:How it is and how it might be. J Int Neuropsychol Soc, 3:487-96.

Wilson BA, Emslie H, Quirk K, et al. 2005. A randomized control trial to evaluate a paging system for people with traumatic brain injury. Brain Inj, 19:891-4.

Wilson BA, Emslie HC, Quirk K, et al. 2001. Reducing everyday memory and planning problems by means of a paging system: a randomised control crossover study. J Neurol Neurosurg Psychiatry, 70:477-82.

Wilson BA, Scott H, Evans J, et al. 2003. Preliminary report of a NeuroPage service within a health care system. NeuroRehabilitation, 18:3-8.

Winnick TA. 2007. Trends in attention to complementary and alternative medicine in the american medical literature. Health (London), 11:371-99.

Winter CD, Pringle AK, Clough GF, et al. 2004. Raised parenchymal interleukin-6 levels correlate with improved outcome after traumatic brain injury. Brain, 127:315-20.

Wozniak JR, Krach L, Ward E, et al. 2007. Neurocognitive and neuroimaging correlates of pediatric traumatic brain injury: a diffusion tensor imaging (DTI) study. Arch Clin Neuropsychol, 22:555-68.

Wright DW, Kellermann AL, Hertzberg VS, et al. 2007. ProTECT: a randomized clinical trial of progesterone for acute traumatic brain injury. Ann Emerg Med, 49(4):391-402.

Wright P, Rogers N, Hall C, et al. 2001a. Enhancing an appointment diary on a pocket computer for use by people after brain injury. Int $J$ Rehabil Res, 24:299-308

Wright P, Rogers N, Hall C, et al. 2001b. Comparison of pocket-computer memory aids for people with brain injury. Brain Inj, 15:787-800.

Xu B, Michalski B, Racine RJ, et al. 2004. The effects of brain-derived neurotrophic factor (BDNF) administration on kindling induction, trk expression and seizure-related morphological changes. Neuroscience, 126:521-31

Xu J, Rasmussen IA, Lagopoulos J, et al. 2007. Diffuse axonal injury in severe traumatic brain injury visualized using high-resolution diffusion tensor imaging. $J$ Neurotrauma, 24:753-65.

Yasokawa YT, Shinoda J, Okumura A, et al. 2007. Correlation between diffusion-tensor magnetic resonance imaging and motor-evoked potential in chronic severe diffuse axonal injury. J Neurotrauma, 24:163-73.

Yasuhara T, Shingo T, Date I. 2004. The potential role of vascular endothelial growth factor in the central nervous system. Rev Neurosci, 15:293-307.

Yeo RA, Phillips JP, Jung RE, et al. 2006. Magnetic resonance spectroscopy detects brain injury and predicts cognitive functioning in children with brain injuries. $J$ Neurotrauma, 23:1427-35.

Zhang L, Abreu BC, Masel B, et al. 2001. Virtual reality in the assessment of selected cognitive function after brain injury. Am J Phys Med Rehabil, 80:597-604; quiz 605.

Zhang L, Abreu BC, Seale GS, et al. 2003. A virtual reality environment for evaluation of a daily living skill in brain injury rehabilitation:Reliability and validity. Arch Phys Med Rehabil, 84:1118-24.

Zhao J. 2003. Acupuncture treatment of facial paralysis caused by craniocerebral trauma in 50 cases. $J$ Tradit Chin Med, 23:47-8.

Zhou Z, Daugherty WP, Sun D, et al. 2007. Protection of mitochondrial function and improvement in cognitive recovery in rats treated with hyperbaric oxygen following lateral fluid-percussion injury. J Neurosurg, 106:687-94

Zhu J, Zhou L, XingWu F. 2006. Tracking neural stem cells in patients with brain trauma. $N$ Engl J Med, 355:2376-8. 